\title{
Study of the Process of Lubricant Application on the Friction Surface Using Aerosol Lubricators
}

\author{
Serhii Voronin $^{1 *}$, Ivan Hrunyk ${ }^{2}$, Bashir Asadov ${ }^{3}$, Dmytro Onopreychuk ${ }^{1}$, Volodymyr Stefanov ${ }^{1}$ \\ ${ }^{1}$ Ukrainian State University of Railway Transport \\ ${ }^{2}$ Regional branch "Lvivska zaliznitsia" Public Joint Stock Company "Ukrzaliznytsia" \\ ${ }^{3}$ Closed joint-stock company "Azerbaijan Railways" \\ *Corresponding author E-mail: voronin.sergey@ukr.net
}

\begin{abstract}
The problem of calculation and forecasting main parameters of aerosol lubricators designed for applying lubricants on angled to the horizon friction surfaces e.g. the lateral surfaces of a rail and a wheel flange of railway rolling stock is solved in the article. The main parameters of lubricators being considered in the article are compressed air supply, the geometry of a spray nozzle and the boundary thickness of a lubricant layer applied to the friction surface where there is no creep of a lubricant under the action of gravity. A structural model of application and retention of a lubricant on a friction surface has been proposed. A mathematical model to calculate main parameters of aerosol lubricators has been developed. The model establishes the connection between the geometry of lubricated friction surfaces, physico-chemical properties of lubricants and the diameter of nozzle aperture and the compressed air supply. The example of calculation of the boundary thickness of a lubricant layer applied to the friction surface under the condition of the absence of its creeping under the action of gravity has been presented in the article. The article presents the results of experimental studies the process of aerosol application of a lubricant to the friction surface.
\end{abstract}

Keywords: aerosol; lubricator; friction surface; rail; wheel.

\section{Introduction}

One of the promising methods of preventing wear and tear of rails and wheels of railways which is being developed actively nowadays is the application of lubrication [1-5]. This method is being investigated and introduced in many countries of the world. It is implemented by means of introduction of stationary rail lubricators and suspended flange lubricators of varied designs. According to the method of application of lubricants, two types of lubricants can be distinguished which are widely used on railways, namely: lubricators with direct-acting (hydrodynamic) nozzles and aerosol lubricators in which liquid lubricant (oil) is applied to the friction surface in the form of aerosol that is produced by special nozzles while supplying a lubricant and compressed air simultaneously. The latter is more economical from the point of view of a lubricant and power consumption, but today theoretical researches of the process of aerosol application are unavailable. However, these investigations would make it possible to calculate the main parameters of lubricators: a lubricant and compressed air consumption.

\section{Analysis of Recent Studies and Publications}

While realizing aerosol lubrication of a rail surface and/or wheel flange, two main questions should be answered: "How much lubricant does a friction surface need from the point of view of effective lubrication?" and "What maximum portion of a lubricant may be applied on a friction surface without causing its creep under the action of gravity?"
We think that the answer to the first question centres around the researches in the sphere of tribology and resides in the search of the appropriate thickness of a lubricant film on a friction surface where the transition from Coulomb friction to boundary or halfliquid lubrication takes place. According to the existing ideas, the thickness of a lubricant film where the transition from boundary to half-liquid lubrication takes place is determined under the condition [6]

$h_{\text {min }} \geq R_{a 1}+R_{a 2}$

where $R_{a 1}, R_{a 2}$ are arithmetic average roughness heights of contacting surfaces of a rail and a wheel flange.

In other words, the thickness of a lubricant film must exceed arithmetic average roughness heights of contacting surfaces. In this case, the wear and tear of the surfaces will be minimal $[6,7]$. The answer to the second question is determined by means of carrying out the analysis of forces affecting the lubricant applied on the friction surface taking into account the thickness of the applied lubricant and compressed air consumption. If only gravity affects a drop of applied lubricant, then the forces that prevent the drop from creeping from the surface are the force of material adhesion to the surface and the force of viscous friction between the layers of a drop. The adhesion force will be determined according to [8]:

$F_{a}=L \sigma(1+\cos \Theta)$,

where $L$ is wetted perimeter, $\mathrm{m}$; $\sigma$ is surface tension coefficient, $\mathrm{Dg} / \mathrm{m}^{2} ; \Theta$ is limiting wetting angle, grad. 
Friction force is caused by the viscosity of a lubricant and is subject to Newton's law. If to consider that the distribution of liquid according to the height of a drop is realized by a square parabola, then from [9]

$$
F_{m}=\frac{3 \pi \mu V_{k} v_{c}}{h^{2}},
$$

where $\mu$ is a lubricant dynamic viscosity, $\mathrm{Pa} \cdot \mathrm{s} ; V_{k}$ is a drop volume, $\mathrm{m}^{3} ; v_{c}$ is the rate of a drop creep, $\mathrm{m} / \mathrm{s} ; h$ is the height of the applied drop, $\mathrm{m}$.

So, based on the conducted analysis, we established basic dependences which will be used for further investigation.

\section{The Basic Part of the Study}

\subsection{Purpose and Objectives of the Study}

The objective of the study is theoretical and experimental investigation of parameters of lubricant application on the friction zone of the wheel-rail contact using aerosol lubricators.

The following problems have been solved to achieve the objective: a design model for application and dripping has been created; a mathematical model for calculating the limiting thickness of the lubricant layer has been constructed; the limiting thickness of the lubricating layer on the side surface of the rail has been calculated; and experimental studies of aerosol application of the lubricant have been carried out.

\subsection{Development of Mathematical Model}

The following design model of applying a drop and its creeping from the surface under gravity has been proposed (Fig.1).

The equation of a drop movement downwards is determined from the analysis of forces affecting a drop. The creep of a drop occurs when the rare edge of a drop loses contact with the surface. In this case it is necessary to perform work equal to gravity. In this context we can write down the following equation:

$m g \sin \alpha=F_{a}+F_{m}$,

where $m-$ is the weight of a drop, $\mathrm{kg}$ :

$m=V_{k} \rho$,

$V_{k}=\frac{\pi d^{3}}{6}$,

where $d$ - is the diameter of a drop, $\mathrm{m} ; \rho$ - is the density of a lubricant, $\mathrm{kg} / \mathrm{m}^{3} ; g-$ is the acceleration of free fall, $\mathrm{m} / \mathrm{s}^{2} ; \alpha-$ is a friction surface canting angle, grad.

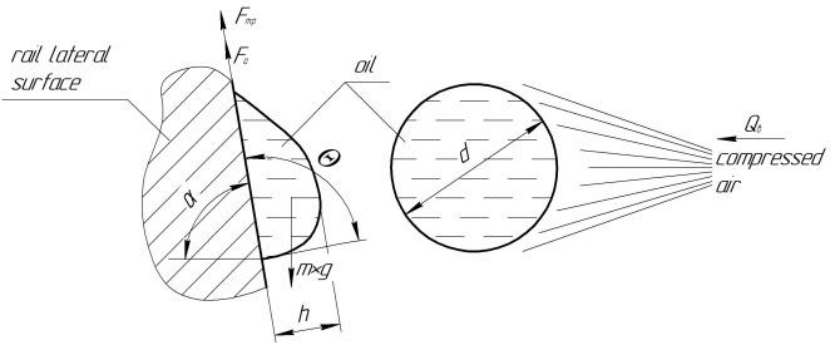

Fig. 1: Design model of a mathematical model construction.

So, the condition of the absence of a drop detachment will be determined by the expression: $m \leq \frac{F_{a}+F_{m}}{g \cdot \sin \alpha}$

The adhesion force of a drop is determined according to the formula (2) in which wetted perimeter equals

$L=\pi d_{k}$

where $d_{k}-$ is the diameter of a contact area of a drop with the surface, $m$.

The diameter of a drop contact area taking into account its spreading is determined by the empirical dependency [10]:

$d_{k}=d \cdot\left(\frac{\delta}{d}\right)^{0,204} \cdot\left(\frac{v^{2} \cdot \rho \cdot d}{\sigma}\right)^{0,227-0,186 \frac{\delta}{d}}$,

where $\delta$-is the thickness of a trapping layer (in a first approximation $\left.\delta \approx h_{\min }\right), \mathrm{m} ; v-$ is the rate of a drop on impact with the surface, $\mathrm{m} / \mathrm{s}$.

The rate of a drop for a pneumatic nozzle can be approximately taken as being equal to the rate of air flow $v_{B}$, then:

$v=v_{\beta}=\frac{4 Q_{6}}{\pi d_{6}^{2}}$,

where $Q_{b}$ is air supply, $\mathrm{m}^{3} / \mathrm{s} ; d_{6}$ is the diameter of an air port of a nozzle, $\mathrm{m}$.

Taking into account the dependences (6), (8) - (10) the condition of creep absence (7) will become:

$$
m \leq \frac{\pi d\left(\frac{h_{\min }}{d}\right)^{0,204} \cdot\left(\frac{\left(\frac{4 Q_{s}}{\pi d_{s}^{2}}\right)^{2} \rho d}{\sigma}\right)^{0,227-0,186^{\frac{h_{\min }}{d}}} \cdot \sigma(1+\cos \Theta)+\frac{\pi^{2} \mu d^{3}}{2 h^{2}} \cdot v_{c}}{g \cdot \sin \alpha} .
$$

The obtained dependency (11) represents the mathematical model of the process of application and retention of a lubricant drop on an angled friction surface. It connects minimal required thickness $h_{\min }$, the thickness of a drop that don't creep, $h$, physico-chemical properties of a lubricant $-\sigma, \mu$ and the parameters of air supply $Q_{b}, d_{\theta}$. This model can be used while designing aerosol lubricators.

\subsection{Rationale of Requirements for Lubricants}

One of the key issues in the study and development of aerosol type lubricators is the rationale of the requirements for the lubricant being used. Such rationale is based on the investigation of the physical basis of the interaction of the lubricant with the metal friction surface, as well as the spraying process by the injector.

The main requirements for lubricants are the maximum adhesion to the solid friction surface and the minimum cohesion between their molecular layers [11]. In this case, minimum frictional forces in a wide load range can be achieved. For this purpose, surfaceactive agents (SAA) - additives, whose molecules have an electric dipole moment - are added to the base lubricants to form of crystalline boundary layers on the friction surfaces. Such layers, according to previous studies [11], have the properties of liquid crystals, that is, high bearing capacity in the normal direction and low resistance to the tangential displacement (Fig. 2).

The principal SAAs used as anti-wear and antifriction additives include oil-soluble fatty acids, such as stearic, oleic, lauric, and others. They have a high dipole moment and a filamentous elongated structure. The main properties of these surfactants are not 
only high surface activity, but also their ability to form colloidal solutions in the base oil, that is, they are present in the solution not in the form of single molecules, but in the form of molecular aggregates with the aggregation number from several molecules to several thousand molecules, depending on the concentration, and rather low surface activity due to a specific structure, when the polar parts of the molecules are in the nucleus of the aggregate, while non-polar ones are outside.

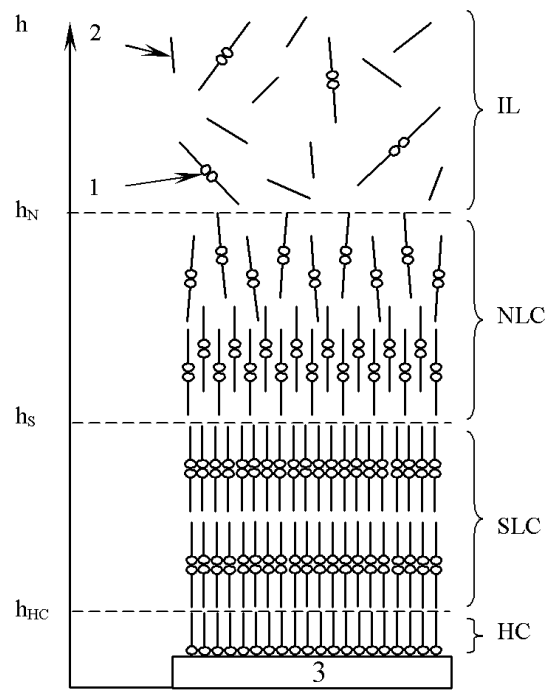

Fig. 2: Structure of the crystalline boundary layer on the metal friction surface: 1 - dimmer of the additive; 2 - molecule of the base oil; 3 - friction surface; $h_{\mathrm{HC}}$ - hard crystalline layer thickness; $\mathrm{h}_{\mathrm{S}}$ - smectic layer thickness; $h_{N}-$ nematic layer thickness. IL - isotropic liquid; NLC - nematic liquid crystal; SLC - smectic liquid crystal; HC - hard crystal.

According to studies conducted in [11], conditions for efficient formation of the liquid crystal SAA layer can be achieved on the friction surface (Fig. 2) due to influencing of the external electrostatic field on the additive aggregates. The additive aggregates affected by such a field are restructured into highly ordered molecular "packages" with a significantly high dipole moment.

The boundary layer shown in Fig. 2 is formed on the actual contact area, that is, on the worn-out tips of the microscopic asperities of the friction surfaces, which keep being formed due to the elastic-plastic contact, displacement, or cut of the microscopic projections. If the bearing capacity of the boundary layer is less than the effective contact pressure on the surface, then such a layer will be destroyed and fail to perform its functions.

Another condition must be fulfilled in order to reduce the contact pressure in the "wheel-rail" friction pair - two-layer lubrication of surfaces. It is known that in the two-layer lubrication, the first layer - the substrate - distributes the external load by filling microscopic asperities, while the second layer - the crystalline SAA layer - absorbs the external distributed load (Fig. 3).

Micro- or nanoparticles of metals, graphite, molybdenum disulfide, natural minerals, etc. are used as dopant additives. In order to stabilize them in a base oil solution, they are coated with a thin film of oil-soluble SAAs before blending.

Based on the above information, the following basic requirements for lubricants can be established, which can be recommended for use in aerosol lubricators:

1. The lubricant must contain microscopic dopant SAA-coated particles which have high adhesion to the surface.

2 . The lubricant must contain a sufficient amount of additives to form a crystalline boundary film on the worn tops of the microscopic asperities of friction surfaces.

3. The lubricant must have the adequate viscosity and temperature characteristics to ensure efficient spraying.
Lubricants doped with graphite or molybdenum disulfide particles, for example Liqui Moly 10W40 engine oil, which is proposed for use, comply with the above requirements.

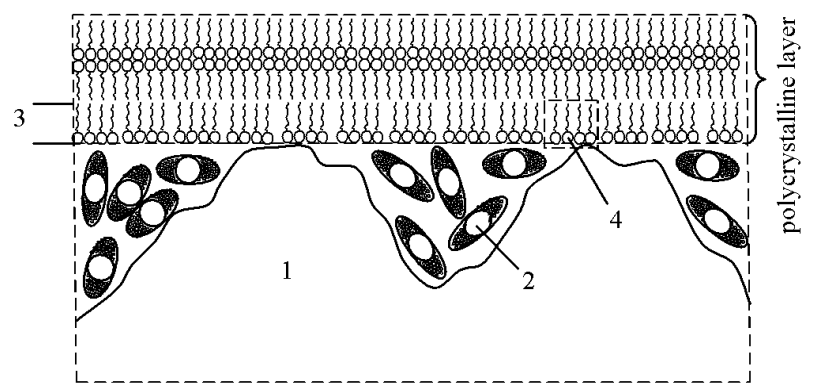

Fig. 3: Physical diagram of two-layer lubrication of friction surfaces: 1 friction surface; 2 - dispersion dopant additives with SAA coating; 3 monocrystalline additive layer; 4 - "packages" of additives.

Photomicrographs of Liqui Moly 10W40 engine oil samples were taken in the certified applied research tribochemical laboratory of UkrSURT using a specifically developed digital microscope, to identify the presence of molybdenum disulfide particles and their size in the proposed lubricant (Fig. 4).

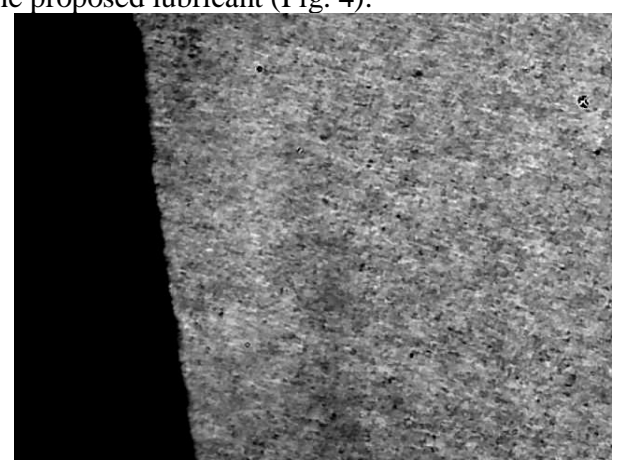

Fig. 4: Photomicrograph of Liqui Moly 10W40 $(\times 1000)$ engine oil sample.

According to Fig. 4, the maximum molybdenum disulfide particle size does not exceed $2 \mu \mathrm{m}\left(2 \times 10^{-6} \mathrm{~m}\right)$. Thus, such particles may be used for filling microscopic asperities of the rail and wheel surfaces and forming the base layer for two-layer lubrication, since their roughness parameters are about 60 to $80 \mu \mathrm{m}\left(8 \times 10^{-5} \mathrm{~m}\right)$.

\subsection{Results of the Calculation and Discussion}

Let's make calculations according to the mathematical model (11). Let's take the following initial data:

- air supply $Q_{b}=0$ to $7 \times 10^{-4} \mathrm{~m}^{3} / \mathrm{s}$;

- the thickness of a trapping layer, $\delta=h_{\min }=10^{-5} \mathrm{~m}$;

- the diameter of an air port of a nozzle, $d_{6}=1.5 \times 10^{-3} \mathrm{~m}$;

- the density of a lubricant, $\rho=880 \mathrm{~kg} / \mathrm{m}^{3}$;

- surface tension coefficient, $\sigma=25.5 \times 10^{-3} \mathrm{Dg} / \mathrm{m}^{2}$;

- a limiting wetting angle, $\Theta=22$ grad;

- liquid dynamic viscosity, $\mu=0.1 \mathrm{~Pa} \cdot \mathrm{s}$;

- an average rate of a drop creeping, $v_{c}=0.05 \mathrm{~m} / \mathrm{s}$;

- friction surface canting angle, $\alpha=80 \mathrm{grad}$.

The results of the calculations of the condition under which a lubricant drop is rolling down the friction surface and boundary thickness of a drop as the function of air supply are presented in Fig. 5 and Fig. 6. Fig 5 shows the method of determination of boundary thickness of an applied drop $h_{b}$ and Fig. 3 shows the dependency of the change of an applied drop boundary thickness from compressed air supply at constant value of an air port diameter. 


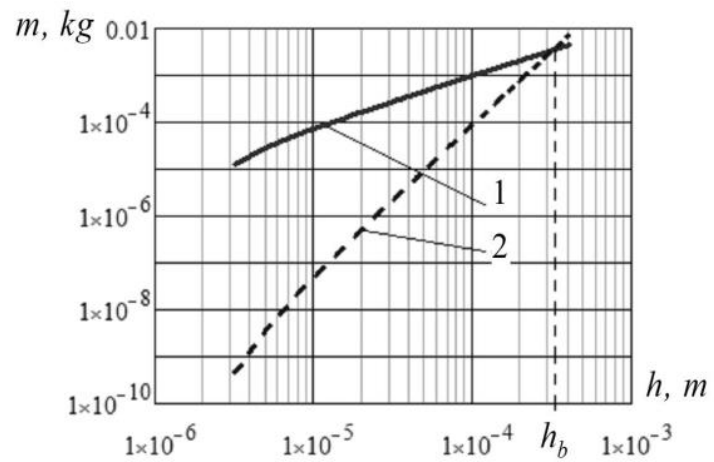

Fig. 5: The dependency of a right part of the expression (11) - 1 and the weight of a lubricant drop -2 from the thickness of a drop applied on a friction surface (air supply is $5,83 \times 10^{-4} \mathrm{~m}^{3} / \mathrm{s}$ ).

In accordance with the method given in Fig. 5, the boundary thickness of an applied drop is established at the intersection of curves 1 and 2. Boundary thickness is understood as such drop thickness at which no creeping occurs. In conformance with Fig. 5, the value of boundary thickness substantially (more than 10 times) exceeds the value of a trapping layer $-h_{b}=1,22 \times 10^{-4} \mathrm{~m}$ against $h_{\min }=10^{-5} \mathrm{~m}$. That is, a lubricant is applied on the surface with a certain "reserve" which is spent to lubricate other part of a surface, for example, by means of spreading a lubricant in the course of wheel movement on a rail.

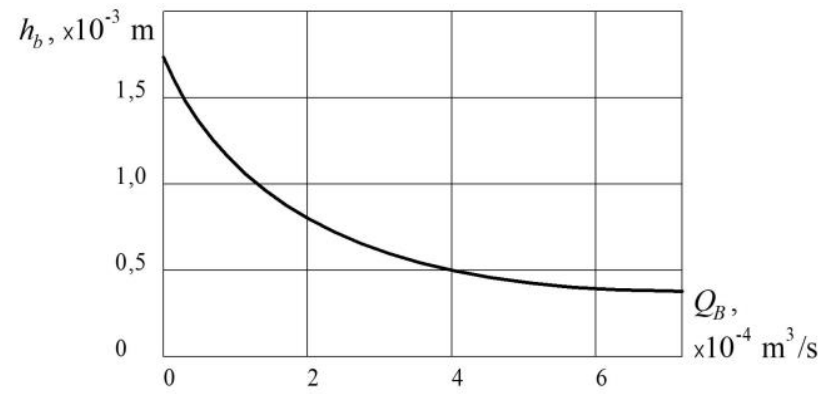

Fig. 6: The dependency of an applied drop boundary thickness on air supply.

While realizing aerosol lubrication of rails and wheel flanges, the regulation of a lubricant layer thickness applied on a surface within one dose can be performed at the expense of the change of compressed air supply and the diameter of a nozzle orifice. Besides, it is also necessary to take into account a material viscosity and the roughness of a friction surface being lubricated.

In production, when the parameters of nozzles and the type of a lubricant are determined and fixed, the boundary thickness is reasonable to regulate by the compressed air supply, according to the graph shown in Fig. 6. Similar curves, which would take into account all the list of factors included into the mathematical model (11), can be drawn at the stage of lubricator designing.

\subsection{Experimental Study of the Process of Aerosol Ap- plication of a Lubricant}

Using a nozzle with the coaxial lubricant and air supply with the $60^{\circ}$ conical frustrum is proposed to spray the air-lubricant mixture (Fig. 7).

The lubricant application stain should not exceed the geometrical dimensions of the working lateral surface of the rail head which is $20 \mathrm{~mm}$ [12]. Its spreading under the action of the wheel flange also should be taken into account, therefore we accept the limiting width being $15 \mathrm{~mm}$.

Subject to the geometrical characteristics of the accepted pneumatic atomizer and the distance at which it is installed from the lateral surface of the rail head, the spraying area should be determined experimentally as a function of the lubricant and air supply rates and taking into account the limiting lubricant thickness $h_{b}$, the reasonable lubricant and air supply rates by the lubricating system and the spraying time should be determined to obtain the necessary width of the lubricant stain and observance of the condition of the lubricant not flowing down the lateral surface of the rail.

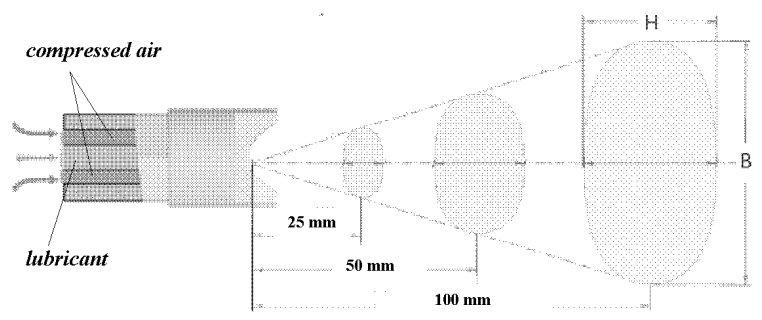

Fig. 7: Nozzle parameters.

Table 1: Shape of the sprayed mixture depending on the distance

\begin{tabular}{|c|c|c|}
\hline Distance, $\mathrm{mm}$ & $\mathrm{H}, \mathrm{mm}$ & $\mathrm{B}, \mathrm{mm}$ \\
\hline 25 & 20 & 50 \\
\hline 50 & 40 & 85 \\
\hline 100 & 45 & 115 \\
\hline
\end{tabular}

Previous experimental studies have shown that the range of the lubricant and air supply rate, at which a lubricating stain is formed, is as follows:

- air supply rate $Q_{b}=19$ to $33 \mathrm{l} / \mathrm{min}$;

- lubricant supply rate $Q_{m}=1.26 \times 10^{-3}$ to $1.9 \times 10^{-3} \mathrm{l} / \mathrm{min}$.

The results of the conducted studies within these ranges at the ambient temperature $T=20^{\circ} \mathrm{C}$ are shown in Fig. 8 .

According to the analysis of diagrams in Fig. 8, the limiting width of the lubricant stain $B=15 \mathrm{~mm}$ can be achieved in two cases:

- lubricant supply rate $Q_{m}=1,9 \times 10^{-3} 1 / \mathrm{min}$ and air supply rate $Q_{6}=26 \mathrm{l} / \mathrm{min}$;

- lubricant supply rate $Q_{m}=1,58 \times 10^{-3} 1 / \mathrm{min}$ and air supply rate $Q_{6}=33 \mathrm{l} / \mathrm{min}$.

Then we can determine the limiting thickness of the lubricant film $h_{b}$ provided the lubricating layer of the materials is not detached (Fig. 8) taking into account that the wetted perimeter is determined as half of the perimeter of the elliptical area of the lubricant stain.

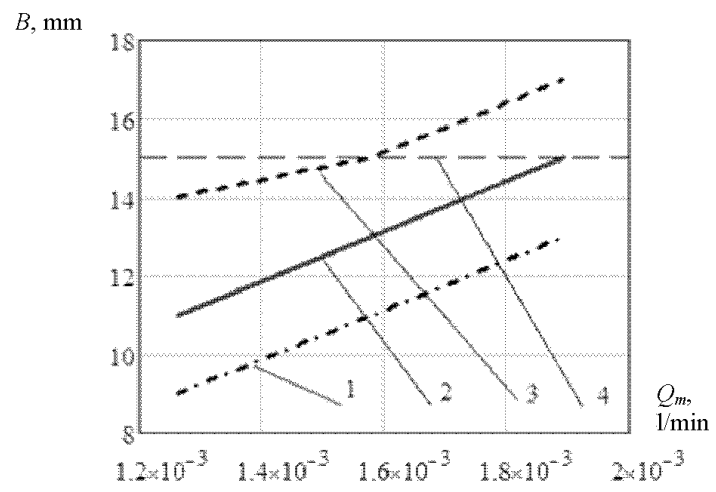

Fig. 8: Dependency of the width of the stain on the lubricant supply rate at $t=5 \mathrm{sec}\left(1-Q_{6}=19 \mathrm{l} / \mathrm{min} ; 2-Q_{6}=26 \mathrm{l} / \mathrm{min} ; 3-Q_{6}=33 \mathrm{l} / \mathrm{min} ; 4-\right.$ limit ing width of the stain $15 \mathrm{~mm}$ ).

The wetted perimeter can be determined by the formula:

$L=\frac{\pi}{2} \cdot\left(0,75(B+H)-\sqrt{\frac{B H}{4}}\right)$

where $B, H$-width and length of the lubricant stain, $\mathrm{m}$. The results of calculating the limiting thickness of the lubricating film on the lateral surface of the rail are shown in Fig. 9. 


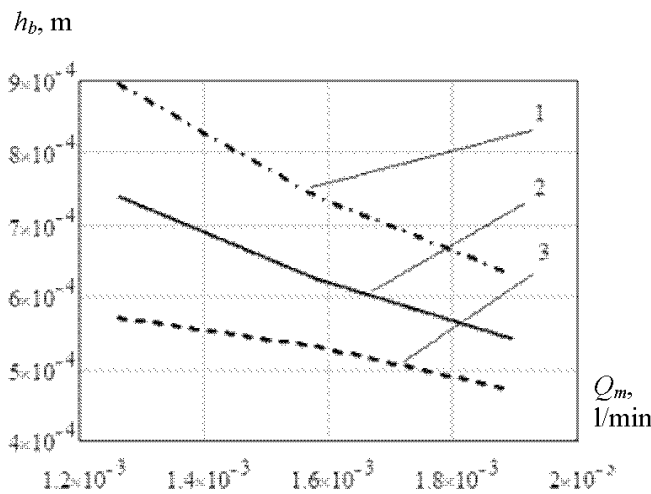

Fig. 9: Dependency of the limiting thickness of the lubricant thickness on the lubricant supply rate $\left(1-Q_{6}=19 \mathrm{l} / \mathrm{min} ; 2-Q_{6}=26 \mathrm{l} / \mathrm{min} ; 3-Q_{6}=33\right.$ $1 / \mathrm{min})$.

According to the analysis of the diagrams in Fig. 9, the following limiting thickness corresponds to the selected lubricant and air supply rates which enable to achieve the required width of the lubricant stain:

$-h_{b}=0.55 \times 10^{-3} \mathrm{~m}\left(Q_{m}=1.9 \times 10^{-3} 1 / \mathrm{min}, Q_{b}=261 / \mathrm{min}\right) ;$

$-h_{b}=0.52 \times 10^{-3} \mathrm{~m}\left(Q_{m}=1.58 \times 10^{-3} 1 / \mathrm{min}, Q_{b}=331 / \mathrm{min}\right)$

Upon determination of the limiting thickness of the lubricant film and knowing the area of the lubricant stain and the lubricant supply rate, we can obtain the limiting spraying time from the formula

$t_{b}=\frac{\pi B D h_{b}}{4 Q_{m}}$

The results of the calculation of the limiting spraying time are shown in Fig. 10.

The analysis of the obtained results shown in Fig. 10 demonstrates that for the selected cases of lubricant and air supply, which enable to achieve the necessary width of the lubricant stain $\mathrm{B}=15$ $\mathrm{mm}$, its limiting spraying time is:

$-t_{b}=8.9 \mathrm{sec}\left(Q_{m}=1.9 \times 10^{-3} 1 / \mathrm{min}, Q_{b}=261 / \mathrm{min}, h_{b}=0.55 \times 10^{-3}\right.$ $\mathrm{m})$

$-h_{b}=11.9 \mathrm{sec}\left(Q_{m}=1.58 \times 10^{-3} \mathrm{l} / \mathrm{min}, Q_{b}=33 \mathrm{l} / \mathrm{min}, h_{b}=\right.$ $\left.0.52 \times 10^{-3} \mathrm{~m}\right)$

$t_{b}, \mathrm{~m}$

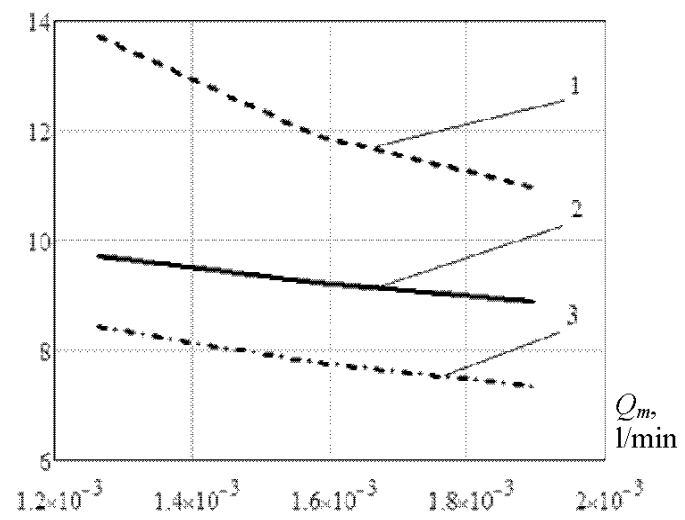

Fig. 10: Dependency of the limiting spraying time on the lubricant supply rate $\left(1-Q_{b}=19 \mathrm{l} / \mathrm{min} ; 2-Q_{6}=26 \mathrm{l} / \mathrm{min} ; 3-Q_{b}=33 \mathrm{l} / \mathrm{min}\right)$.

In view of this, the first considered case should be taken for substantiation of the parameters of the aerosol lubricators, since the material spraying time is shorter, while the thickness of the lubricating film is more vs. the second case. This allows for better leveling and material distribution along the lateral rail head.

\section{Conclusion}

The task on creating the model of forecasting and calculating the main parameters of aerosol lubricators has been solved in the conducted research. The main parameters include the compressed air supply, the geometry of spray nozzles and the boundary thickness of a lubricant layer, applied on the friction surface.

A mathematical model that allows obtaining the main feature of aerosol lubricators, namely, the connection between the thickness of a lubricant layer and the compressed air supply has been proposed in the research. Such model takes into account the geometry of friction surfaces being lubricated, physico-chemical properties of a lubricant. It can be used both at the designing stage and at the stage of adjustment of aerosol rail and flange lubricators.

Experimental study of the aerosol application process support the design result obtained using the developed mathematical model.

\section{References}

[1] Danilenko E.I., Zaliznychna koliya. Ulashtuvannya, proektuvannya i rozrahunki, vzaiemodiya $\mathrm{z}$ ruhomim skladom, Inpres, Kyiv, (2010), V.1, 528 p.

[2] Lysikov E.M., Astahov V.M., Voronin S.V., Tuley Yu.L., Shliakhy udoskonalennia strilochnykh perevodiv zaliznyts Ukrainy pry vykorystanni system dozovanoho vvodu mastylnykh materialiv, Visnyk Donetskoho instytutu zaliznychnoho transportu, №. 24, (2010), pp.5-10.

[3] Voloshko Yu.D., Orlovskiy A.N., Kak rabotaiut strelochnye perevodi pod poezdamy, Transport, Moskva, (1987), $120 \mathrm{p}$.

[4] Bogdanov V.M., Zaharov S.M., Sovremennye problemy systemy koleso - rels, Zheleznble dorohy myra, №. 1, (204), pp.25-33.

[5] Lysikov E.N., Skorik A.A., Povyshenye resursa tekhnycheskykh system zheleznodorozhnoho transporta putem ispolzovanyia nanotekhnolohyi, Zaliznychnyi transport Ukrainy, №. 4, (2010), pp.6061 .

[6] A. V. Chichinadze, E. M. Berliner, E. D. Braun, Trenie, iznos i smazka (tribologiya i tribotechnika, Mashinostroenie, Moscow, (2003), $576 \mathrm{p}$

[7] S. Voronin, O. Skoryk, V. Stefanov, D. Onopreychuk, Ye. Korostelov, Study of the predominant defect development in rails of underground systems after preventive grinding and lubrication, MATEC Web of Conferences, 116, 03005, (2017).

[8] A. D. Zimon, Adhezia gidkosti i smachivanie, Himiya, Moscow, (1974), 416 p.

[9] N. E. Kochin, I. A. Kibel', N. V. Roze, Teoreticheskaya gidromehanika. Ch.II, Phizmatgiz, Moscow, (1963), 728 p.

[10] L. A. Vitman, B. D. Katsnelson, I. I. Paleev, Raspylivanie gidkosti phorsunkami, Gosenergoizdat, Moscow - Leningrad, (1962), 265 p.

[11] S. Voronin, Development of tribophysical foundations of lubricity of liquidcrystal additives to base oil, EasternEuropean Journal of Enterprise Technologies, Vol.3, No.7, (2015), pp.53-57.

[12] S. Voronin, I. Hrunyk, V. Stefanov, A. Volkov, D. Onopreychuk, Research into frictional interaction between the magnetized rolling elements, EasternEuropean Journal of Enterprise Technologies, Vol.5, No.7-89, (2017), pp.11-16. 